\title{
Motivating students for distance learning in the context of the COVID-19 pandemic
}

\author{
Sergey Yekimov ${ }^{1, *}$, Oksana Danylovych ${ }^{2}$, Viktoriya Baidala $^{3}$, Larysa Vasylieva $^{4}$, and Oleh \\ Mikhailychenko ${ }^{5}$ \\ ${ }^{1}$ Publishing House "Education and Science" s.r.o., Olstynska 607/1, Praha 8, 18100, Czech Republic \\ ${ }^{2}$ Yuriy Fedkovych Chernivtsi National University, Chernivtsi, Ukraine \\ ${ }^{3}$ H.S. Skovoroda Kharkiv National Pedagogical University, Kharkiv, Ukraine \\ ${ }^{4}$ Sukhomlynskyi Mykolaiv National University, Mykolaiv, Ukraine \\ ${ }^{5}$ Sumy State Pedagogical A.S. Makarenko University, Sumy, Ukraine
}

\begin{abstract}
Distance learning based on the use of telecommunications technologies allows not only to communicate with the use of a foreign language, but also to gain an understanding of foreign culture and history, but also to gain skills in the use of a foreign language in order to solve professional problems. By participating in telecommunications projects, students become more interested in actively participating in the educational process. Team creative activity of students aimed at solving various communication tasks increases, in our opinion, the motivation to acquire new knowledge and skills. In connection with the COVID-19 pandemic, students of many educational institutions were transferred to distance learning. From this point on, students could study some academic disciplines through the use of interactive technologies. However, the transition of all subjects to distance learning was an unpleasant surprise for many students. Teachers of the course of foreign languages for students of non-linguistic specialties began to note a decrease in student performance as a result of the transition to distance learning of foreign languages. We attribute this decrease to a decrease in students ' motivation to participate in the educational process. We suggested using the project method to increase motivation for distance learning of a foreign language. At the end of the academic semester, teachers who teach foreign languages for students of non-linguistic specialties noted the progress of the students ' reading skills in technical literature corresponding to their chosen profession.
\end{abstract}

\section{Introduction}

Distance learning allows you to organize the learning process through communication and information technologies and technical means in which the students and the teacher are located in different places. It usually does not regulate the territorial and time limits of the learning process.

*Corresponding author: 3701313@mail.ru 
According to [1], distance learning is an educational service provided through an educational and information environment that uses long-distance data exchange tools.

According to [2], distance learning is a combination of computer, pedagogical, and telecommunications technologies that allow you to conduct training remotely from an educational institution.

According to [3], the most interested in distance learning are people who want to:

1) Independently increase their competencies.

2) Study according to a convenient schedule.

3) Have access to training when full-time training is not possible.

4) Apply their own individual ways of studying the training material.

5) Engage in training in a comfortable environment.

Authors of [4] synchronous and asynchronous form of distance learning. The synchronous form of distance learning includes video conferences, chat rooms, and webinars. Asynchronous forms of distance learning include e-mail, blogging, social networking, and the use of electronic textbooks.

The synchronous form of distance learning regulates the simultaneous presence of a teacher and a student in the educational process.

The asynchronous form of distance learning is based on access to the educational methodological base without time and spatial restrictions.

According to [5], the distance learning method of foreign languages provides an opportunity to:

1. Develop listening, reading and translation skills;

2. Develops the ability to communicate in writing;

3. Gives you the opportunity to replenish your vocabulary.

4. Promotes successful memorization of grammatical and lexical constructions.

5. Promotes the formation of socio-cultural and communicative competencies

According to [6], distance learning in foreign languages can be the optimal form of learning if the trainees:

1) Have a place of residence in remote areas;

2) They want to independently plan the schedule and time of classes, as well as the list of subjects studied;

3) Independently learns an additional foreign language;

4) Constantly change their place of residence;

5) Have health problems or are related to people with disabilities.

6) Have a desire to systematize or improve their existing knowledge.

The possibilities of modern communication technologies allow you to get acquainted with the customs and culture of the country whose language is being studied, as well as to communicate and listen to native speakers in the process of remote learning of a foreign language .

According to [7] distance learning has a number of specific features: students and teacher should know and be able to use software and hardware, training should be well planned, because of its remoteness teacher trainees for the formation of learning communities of teacher requires certain skills and effort, synchronous distance-learning requires periodic verification of the degree of involvement of the learners in the learning process.

According to [8] distance learning through the use of the Internet allows you to solve a number of didactic problems:

1) Improve the students ' skills of dialogic and monological utterance;

2) To form students ' competence to read texts in a foreign language.

3) Improve the students ' writing skills in a foreign language. 
According to [9], the asynchronous form of distance learning in a foreign language is less interactive compared to the synchronous form. However, the asynchronous form has the advantage that the trainees have the opportunity to receive training information at the optimal time for them. They also have time to reflect on the information received and think about their response. Since the asynchronous form of distance learning usually involves the use of e-mail, this simplifies the communication process between the listener and the teacher.

According to [10], the synchronous form of distance learning of a foreign language is preferred if the parties involved in the learning process are ready to communicate at a given time.

According to [11], for learning a foreign language, the possibility of direct communication between the teacher and the student is preferable, but by combining asynchronous and synchronous teaching methods, it is possible to achieve certain success in teaching a foreign language.

The authors [12] distinguish the functions of remote learning of foreign languages (Figure 1):

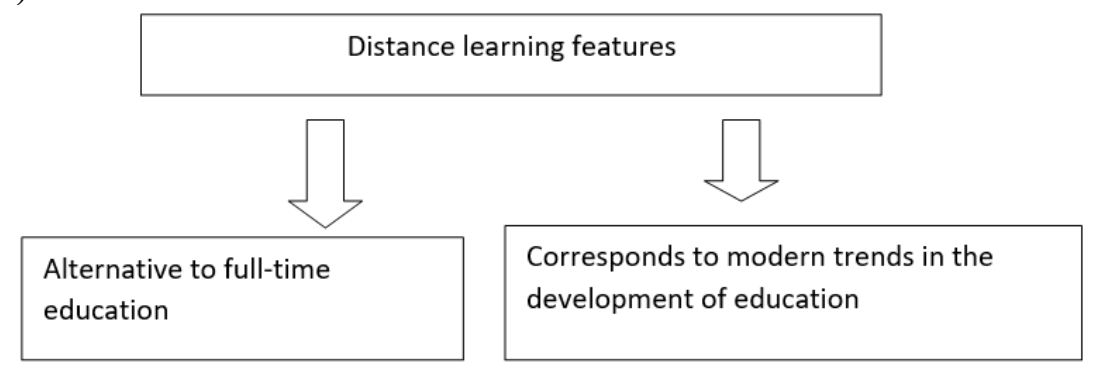

Fig. 1. Distance learning features

The authors [13] identify a number of methodological principles that are of primary importance for distance learning of a foreign language:

1) The principle of clarity (the educational material should contain authentic texts that give an idea of the country whose language is being studied).

2) The principle of accessibility (the use of interactive technologies in the educational process).

3) The principle of communicative activity (achieved through contacts between the teacher and students, as well as between students during the performance of educational tasks).

4) The principle of motivating the student to gain new knowledge on the part of the teacher.

According to [14] for the effective functioning of the educational process in distance learning of a foreign language, it is necessary to have a system for managing the educational process, which in our opinion should provide (Figure 2): 


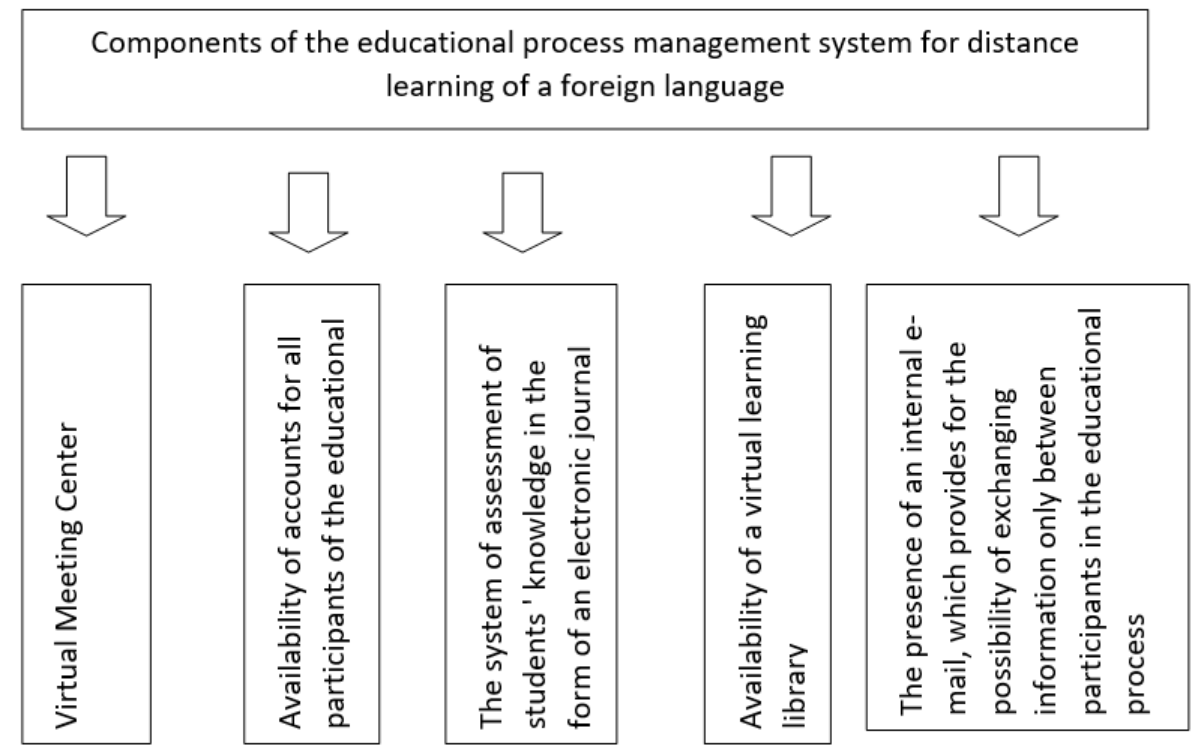

Fig. 2. Components of the educational process management system for distance learning of a foreign language

Despite the significant advantages of distance learning of a foreign language, it has some disadvantages.

According to [16], distance learning makes it difficult to control learning activities. It is not always clear who performs the task and what educational materials the student uses when performing the educational task. If the student is not motivated, it is quite possible that he will try to quickly finish the work on the tasks, only superficially studying the training material.

The authors [16] suggest using online conferences and webinars to monitor the quality of the work performed by the trainees. To a certain extent, this helps to increase the responsibility of the student.

According to [7], since the teacher's control over distance learning is reduced, the teacher cannot be sure that the student is listening to his lecture, and is not engaged in extraneous matters.

According to [6], remote students are usually isolated from their classmates and the teacher, and the lack of communication does not contribute to the motivation of active participation in the educational process.

According to [3] , a teacher of a distance learning course should not only have a good knowledge of a foreign language, but also be able to teach it using remote teaching methods , as well as be able to motivate students to learn.

According to [11], for effective distance learning of foreign languages, students must have the skills of autonomous work, taking into account their individual abilities.

According to [2], communication between the student and the teacher through the use of telecommunications technologies cannot completely effectively replace direct communication.

During distance learning, the functions of the teacher are subject to certain restrictions, and are practically limited to the management of the learning process. The teacher does not have the status of the main source of educational information.

In our opinion, only motivated students will be most interested in improving their listening, writing, and speaking skills. 


\section{Methods}

In the course of this research, we used an analytical method, by which the problems studied in the work were examined in their unity and development.

Taking into account the tasks and goals of this research work, a functional and structural method of carrying out scientific research was used.

This allowed us to consider some issues related to the use of project methodology in the study of a foreign language.

\section{Results}

Based on the analysis, we came to the conclusion that motivation is one of the most important factors influencing the success of the process of distance learning of a foreign language.

Within the framework of this study, we proposed to use the project method to increase the motivation of students of non-linguistic special schools of the Dnipro Polytechnic to learn a foreign language. In connection with the COVID-19 pandemic, students of the Dnipro Polytechnic were transferred to distance learning. Up to this point, students could study some academic disciplines through the use of interactive technologies. However, the transition of all subjects to distance learning was an unpleasant surprise for many students. Teachers of the course of foreign languages for students of non-linguistic specialties began to note a decrease in student performance as a result of the transition to distance learning of foreign languages.

At the beginning of the study, we conducted a survey of students. According to our survey, $68 \%$ of students noted that they felt uncomfortable from the inability to communicate with their fellow students , 58\% of students noted that they had decreased motivation to study due to life difficulties that arose as a result of the COVID-19 pandemic.

We suggested using the project method to increase motivation for distance learning of a foreign language.

Students were invited to make a multimedia presentation of the department for which they are assigned during their studies at the higher educational institution.

This presentation should contain information about the history of the department, its famous graduates, and the areas of scientific activity carried out by the department's employees.

The presentation must be created in a foreign language.

In the process of working on the project, students collected information in electronic libraries, communicated with the teachers of the department through interactive video communication.

By collecting information about well-known department graduates, students have more clearly understood what they can potentially achieve through successful studies. By translating the information used for the project, students were able to become more familiar with professional terminology in English.

The presentation of the project was carried out online using the Zoom software.

At the end of the academic semester, teachers who teach foreign languages to students of non-linguistic specialties noted the progress in the students ' reading skills of technical literature corresponding to their chosen profession.

Discussion

Distance learning allows you to quickly work with various sources of information. For successful training, students must have the skills to search and process information, as well as be able to work with electronic dictionaries and reference books. 
Distance learning through the use of telecommunications allows you not only to communicate in a foreign language, but also to get an idea of a foreign culture, acquire skills in using a foreign language for professional communication.

Through participation in telecommunications projects, the student can be more motivated to carry out active educational activities. Joint creative activity of students associated with the solution of various communication tasks increases their motivation to acquire new knowledge.

Distance learning of foreign languages has certain advantages in comparison with other methods:

1) Gives the opportunity to learn a foreign language to people who, due to a number of circumstances, do not have such an opportunity.

2) The training can be carried out at a convenient pace for the trainees.

Software used for distance education, in our opinion, should have a simple and userfriendly interface, do not require special skills from computer users, compatible with the most common software, be compact and provide automation of the main components of the educational process.

\section{Conclusions}

An analysis of the main tailing damp failures indicates that in $70 \%$ of cases the dams Interactive educational technologies allow you to optimize and improve the effectiveness of distance learning. Computer technology allows you to expand the possibilities for the presentation of educational material . With the help of a differentiated approach to the pace of work of trainees, an individual approach to the learning process is provided. They have the opportunity to study in an optimal place and time for them.

In order for distance learning to be interesting for students, it is necessary to have the appropriate motivation.

In our opinion, to achieve maximum efficiency of learning a foreign language, it is advisable to combine distance and traditional forms of learning.

\section{References}

1. Nadiya Kovbasnyuk, Iryna Styfanyshyn, Distance learning (2020)

2. Kateryna Melnyk, Effectiveness of distance learning (2020)

3. Tatyana Nikulina, Vestnik of North-Ossetian State University, 4, 110 (2020)

4. Muhammad Azeem, Muhammad Quddoos, Anooshay Ejaz, Nadeem Tarique, Javed Iqbal, Arfan Haq, The Professional Medical Journal, 26 (2019)

5. Anna Šmeringaiová, Distance learning in technical subjects, 5324 (2020)

6. Katarzyna Chmielewska, Weronika Ciskowska, Daria Glazik, Dominika Marcinek, Karolina Wojciechowska, Attila Gilányi, Learnability - are we Ready for Distance Learning?, 000465 (2020)

7. Marta Gluchmanova, Effective distance learning at universities, 717 (2020)

8. Z.B. Batchaeva, M.I. Bolurova, I.D. Dudov, R.A. Karakotova, Distance learning in a pandemic. Trends in the development of science and education (2020)

9. K. Postova, N. Polikhun, Iryna Slipukhina, Education and Development of Gifted Personality, 3(78), 63 (2020)

10. Natalia Artebiakina, Svetlana Lukashevich, Volga Region Pedagogical Search, 32, 117 (2020) 
11. Anastasis Nikiforos, Distance Learning and Interactivity (2020)

12. Solikha Allayarova, Distance learning: content, possibilities and disadvantages (2021)

13. Jose Maestre, Ignacio del Moral, Robert Simon, Clinical Simulation in Nursing, 52, 33 (2021)

14. Seda Khadimally, Evaluating Trends and Issues in Distance Learning (2021)

15. Roberto Douglas Costa, Gustavo Souza, Ricardo Valentim, Thales Castro, Cognitive Systems Research, 64, 134 (2020)

16. V.Ya Gelman, Vestnik Vysshey Shkoly, 8 (2020)

17. N. T. Ozcan, R. Ulusay, N. S. Isik, Environ. Earth Sci., 69 (2012) 